\title{
Analog tekst i digital kontekst
}

\author{
Af Maria Skou Nicolaisen
}

\begin{abstract}
Tekst må til stadighed betragtes som den akademiske verdens primoere formidlingsform, hvorfor det synes oplagt at diskutere moderne tekstforståelse i lyset af digitaliseringen, Nedenstående artikel vil fokusere på anvendelse, bearbejdning og produktion af akademisk tekst. Teksten vil tilskrives at have en legitimerende såvel som en strukturerende funktion, hvilket indvirker på loesningen af den pågoeldende tekst. Den vil proklamere, at traditionelle tekst-og loeseformer synes understøttet af digitaliseringen, og diskutere hvordan kvalitativ tekstanalyse stadig har relevans $i$ en digital tidsalder. Formålet med artiklen er, at diskutere hvordan trykkekulturens tekstopscetning og anvendelse satter forskellige loesetilgange $i$ spil, og hvordan disse tilgange er forenelige med digitaliseringen.
\end{abstract}

\section{Indledning}

Artiklen vil fremsætte nogle generelle pointer i forbindelse med digital og humanvidenskabelig tekstproduktion og -tilegnelse. Artiklens omdrejningspunkt vil være en redegørelse af, hvordan analoge og digitale læseformer kan opfattes som dialektiske tilgange. Trykkekulturens karakteristiske lineære præsentationsform modstilles en mere fragmenteret fremstillingsform, der synes intensiveret i forbindelse med digital tekstlæsning. En sådan dualisme synes dog at være for simpel til at beskrive moderne akademisk tekstanalyse, fordi det partikulære og det generelle altid vil indgå i en eller anden form for samspil. Tekstens struktur og delelementer understøtter hinanden. Digitaliseringen skaber en kvantitativ øgning af tilgængeligt tekstmateriale, men denne dataforøgelse fjerner ikke behovet for kvalitativ tekstanalyse, men udvider blot dens anvendelsesmuligheder. Ekstensive og intensive læsestrategier udelukker ikke hinanden, men har forskellige funktioner i forhold til tekstbearbejdningsprocessen. Det overordnede formål med artiklen vil derfor være at påvise vigtigheden af at understrege dialektikken mellem traditionelle og digitale fremstillingsformer, samt hvilke læsetilgange de synes at understøtte.

\section{Digitalisering af tekst}

Introduktion af nye medieformer bliver som regel mødt med en naturlig skepsis (Striphas, 2009, s.2122). Mistro overfor nye formidlings- og produktionsmåder har ligeledes været rettet mod printformatet
Maria Skou Nicolaisen, Cand. Scient. Bibl., European University Institute Library, Firenze (maria.nicolaisen@eui.eu) 
i dennes introduktionsfase (O'Donnell, 1998, s.71; Lyons, 2010, s.185). Denne problematik gælder ikke mindst for den akademiske verden, der også må tilgodese videnskabelige legitimerings- og dokumentationsstandarder. Nye medier klandres for at medføre litterært forfald, fordi økonomisering og effektivisering af tekstproduktion skaber en større fejlmargin (O'Donnell, 1998, s.75-81). Denne potentielle bivirkning kan forsvares, hvis mediet samtidig er tids- og omkostningsbesparende nok til, at det kan betale sig efterfølgende at bruge tid og ressourcer på fejlfinding, efterredigering etc. Digitaliseringen af fagtekster og faglige artikler, særligt peer-reviewede artikler til faglige tidsskrifter, synes meget inspirerede af deres analoge forgænger - den trykte tekst. Med videnskabelige artikler og akademiske tekster forstås primært fagteoretiske tekster, der benyttes i forskningssammenhænge, skrevet af forskere i og for det akademiske miljø og som videnskabelige bidrag til den faglige debat ${ }^{1}$.

Digital tekstproduktion skaber et spændingsfelt mellem nye teknologiske muligheder og et ønske om at bevare den sikkerhed, der findes ved trykkekulturens papirformat ${ }^{2}$. Videnskabelige artikler er ingen undtagelse, skønt de måske i højere grad end ved mere kommerciel tekstproduktion, udviser forsigtighed i forhold til at udforske mere innovative og interaktive muligheder. Det langsomme indoptag af nye fremstillingsformer inden for bogmediet kan ses som udtryk for en kognitiv magelighed, der må problematiseres eller direkte udfordres for at kunne og ville forny sig (Drucker, 2008, s.3-4). Dog må det samtidig påtænkes at konventionelle kommunikationsformers popularitet afhænger af deres evne til at formidle budskaber hensigtsmæssigt, hvorfor det ikke giver mening at afskrive dem som forældede, men nærmere påtænke, hvorledes de kan indgå i en ny digitaliseret kontekst.

\section{Den tekstuelle dialektik}

Nye og gamle medieformer er af dialektisk art, idet de gensidigt påvirker og påvirkes af hinanden (jf. Liu (A), 2008, s.12-13; Drotner, 2011, s.157) ${ }^{3}$. Vi har et stadigt større indoptag og en stigende produktion af digitalt materiale (jf. Liu (Z), 2008, s.57; Weel, 2011, s.9-10), hvorfor det synes oplagt at diskutere, hvordan analoge og digitale tekster indgår i en dialektisk proces. Om analogt inspirerede digitale tekstfremkomster kun vil være at finde $i$ en art overgangs- periode fra analog til digital tekst ${ }^{4}$, er endnu uvist. Hvad der imidlertid er interessant, er hvorledes disse former interagerer med hinanden - eller for denne artikels udgangspunkt, hvordan analoge repræsentationer kan gengives i en digital kontekst.

Selvom printformatet er et genkendeligt og bemestret læsemedie, er det vigtigt at udfordre og nytænke tekstforståelsen i lyset af den digitale kontekst. Digitaliseringens transformative potentiale er omfatten$\mathrm{de}^{5}$, men det er vigtigt heller ikke at overdrive dens indvirkning på, hvordan vi adresserer og bearbejder tekst. Hertil kommer at vi længe har benyttet os af elektronisk tekstproduktion og -bearbejdning. Digitaliseringens indvirkning på tekstformatet anerkendes imidlertid særligt i forbindelse med informationssøgning. Den mere dybdegående læsning af længere og sammenhængende tekstpassager, som er nødvendig i forbindelse med akademisk litteratur, udtømmes dog ikke med informationssøgningens specifikke punktnedslag, enkeltoplysninger og fragmenterede tekstbidder. Søgemaskinernes maksimeringsstrategi bygger på kvantitativ tilgængelighed og forøgelse af data, men overser til en vis grad behovet for at synliggøre den tekstuelle kontekst (Hjørland, 2012b, s.101-102). Akademisk videnstilegnelse må forudsættes også at behøve kontekstuelt orienterede overbliks- og interaktionsredskaber lige såvel som de behøver bedre søgemaskiner (Mackey, 2012, s.11) ${ }^{6}$.

Tekst er stadig den mest udbredte og anvendte, akademisk formidlingsform, hvorfor den som kommunikationsform også opererer med en opsætning, der i stort omfang har til hensigt at hjælpe læseren (jf. Drucker, 2008, s.7-8)7. E-bøger anerkender eksempelvis deres analoge forgænger og fastholder i mange tilfælde bogformatets opsætning (Sheehan, 2013, s.85). Indenfor e-bogsgenren har man forsøgt på at eksperimentere med mere digital former, men disse har indtil videre ikke haft den store succes (Ibid.) ${ }^{8}$. Det samme kan synes at gøre sig gældende for videnskabelige artikler, hvis opbygning i høj grad også egner sig til at blive udskrevet på papir og ikke blot læst på en skærm ${ }^{9}$.

\section{Medieret tekst}

I forbindelse med såvel analog som digital tekst vil man altid arbejde med en medieret (re-)præsentationsform ${ }^{10}$. Medier vil altid fordre en interaktion mellem mediet som objekt og brugeren som intenti- 
onsgivende subjekt ${ }^{11}$, fordi det er subjektets brug af mediet, der definerer det ved at give det en bestemmelse og et anvendelsesformål (Säljö 2003, 79-84). Hvordan vi forstår, anvender og udnytter mediet, er således relateret til brug. Ud fra en pragmatisk tekstforståelse defineres begreber netop ud fra denne indbyggede anvendelse og brug (Bang, 2011, s.23-24). Vidensmedier vil opnå status af underholdnings- eller vidensmedier gennem deres eksplicitte brug, der ydermere kan opfattes forskelligt i forskellige kontekster og i forhold til hvilket formål de anvendes. Et vidensmedie vil således opnå sin status ved at hjælpe brugeren i en meget bred vidensfaciliteringskontekst. Et tekstmedie vil på samme måde gøre det muligt for brugeren at arbejde med tekst $\mathrm{i}$ en eller anden form. Et digitalt og tekstuelt vidensmedie kan således understøtte tekstuel vidensfacilitering, herunder læsning, tekstbearbejdning og/eller -produktion. Det er netop disse medier og den videnskabende interaktion i forbindelse med tekstbearbejdning, denne artikel forsøger at klarlægge.

I en akademisk kontekst vil tekst- og vidensmedier netop benyttes til at tilegne sig viden, og for tekstmediers vedkommende gøres dette primært via læsning. Vi kan downloade tekst til stationære og bærbare computere eller til tablets ${ }^{12}$, til de til formålet udviklede e-læsere, samt til vores smartphones ${ }^{13}$. Computere har vist sig meget anvendelige i forhold til tekstproduktion, hvorimod papirformatet har været det foretrukne medie for tilegnelse, altså læsning, af tekst - i særdeleshed i forbindelse med større tekstmængder. E-læseren udgør et elektronisk alternativ til papirpogen som læsemedie, og tilbyder også muligheden for at bearbejde tekst, men bruges i udgangspunktet ikke til decideret tekstproduktion. Tablets og smartphones kan, i lighed med og som en art minicomputere, bruges som både læse- og tekstproduktionsredskaber, men deres tilkobling til internettet gør dem i stand til at inkorporere en myriade af anvendelsesmuligheder som underholdningsog informationsmedier. Netop denne tilkobling gør dem dog også til oplagte vidensmedier indenfor en akademisk kontekst. Hvert af disse digitale medier har deres specifikke kendetegn, anvendelsesområder, præsentationsformer og muligheder, men bliver for følgende diskussion betragtet som digitale tekstmedier i ordets bredeste betydning - som digitale medier, der bruges i forbindelse med tekstlæsning og/eller -produktion.

\section{Dynamisk tekst}

Jørgen Bang \& Christian Dalsgaard laver en analytisk differentiering af videns- og informationsbegrebet, eftersom de karakteriserer information som eksternaliserede, formaliserede og transmitterbare enheder, hvorimod viden først fremkommer i internaliserings- eller teksttilegnelsesprocessen -altså først, når den overførte tekst sættes i relation til læseren og dennes forståelseshorisont gennem læseprocessen (Bang \& Dalsgaard, 2008, s.11-14) ${ }^{14}$. Den formidlede tekst finder imidlertid først sin berettigelse i læseprocessen, hvor den sættes i relation til læserens egen tolkning og meningsskabelse. Denne internaliserede, videngjorte information kan herefter overføres til en ny meningsgivende kontekst ved at indgå i læserens aktive videnstilegnelse og potentielt en ny vidensproduktion, hvor den atter transmitteres som formaliseret viden/tekst. På denne måde muliggøres en uendelig betydningsdannelse, fordi teksten potentielt altid vil kunne indgå som del af en ny videnskontekst/tekst ${ }^{15}$. Læseren er således ikke en ukritisk modtager, men en potentiel aktør i realiseringen af tekstens iboende betydningspotentiale som komponent i tekstuelle skabelser og nyskabelser (Evans \& Rees, 2012, s.21).

Ved akademiske tekster bliver denne dynamiske skabelsesproces synliggjort via tekstens referencer. Her forholder forfatteren sig aktivt reflekterende til sit genstandsfelt. Akademiske tekster arbejder meget åbenlyst ud fra en kumulativ vidensopbygning, idet forfatteren eksplicit søger at redegøre for tekstens intertekstualitet; dens tilknytning til andre undersøgelser, teorier, tekstproduktioner, og videnstraditioner ${ }^{16}$. Teksten finder netop sin akademiske berettigelse ved at inddrage, udfordre og bygge videre på andre tekster og indskriver sig derved $i$ en større teksttradition (jf. Hjørland, 2012a, s.68-69). Samtidig opererer den akademiske videnstradition også med et transformativt vidensideal, idet teksten ikke blot gengiver andre tekster, men indsætter dem i en ny kontekst, hvorved formålet med og udtrykket i teksten ændres, øges eller skærpes (Kristiansen, 2010, s.52-53). En akademisk tekst vil derfor altid perspektivere til andre videnskontekster (jf. Cobley \& Haeffner, 2011, s.175), der enten henviser til relationer internt i teksten (struktur, sammenhænge etc.) eller udenfor teksten selv (som referencer og baggrundsantagelser). Tekstudsagn er dynamiske fremkomster. Som trykt tekst kan de muligvis fremstå som afsluttede enti- 
teter, men de vil altid kunne indgå i nye vidensformationer (Tredinnick, 2009, s.39-40). De sproglige tegn indgår i konstant foranderlige meningskonstellationer- og skaber derved nye videnskonstruktioner (Frow, 1990, s.47).

\section{Stabilisering af digital tekst}

Teksten indeholder en intertekstuel dobbelthed, fordi den på den ene side udgår fra en dynamisk teksttradition ${ }^{17}$, men på den anden side fremstår som et sammenhængende, afsluttet og uforanderligt produkt i sin egen ret. Teksten kan særligt i sin fysiske form forekomme at være stabil, men opbygges af midlertidige stabiliseringer af en aldrig fuldendt vidensproces $^{18}$. Trykkekulturens produktionsvilkår nødvendiggjorde en fastlåsning af teksten til papiret, hvor form og indhold derfor udgjorde et samlet hele (Tredinnick, 2006, s.7). Papirbogens indbyggede materialitet har præget opfattelsen af tekst som en stabil formidlingsform, idet indholdet er fastlåst et fysisk medie og derfor kan bruges som relativt sikker dokumentationsform (Tredinnick, 2007, s.59). Denne repræsentationsform tingsliggør teksten ved at "idea and expression are virtually one" (Liu (Z), 2008, s.54). Hvor teksten i sin papirudgave kan forlede læseren til at betragte bogen som et samlet og afsluttet hele, opfordrer den digitale dynamik til, at man udvider denne tekstforståelse (jf. Frow, 1990, s.51).

Digital tekst er ikke på samme måde forankret til et fysisk medie som den trykte tekst er $\operatorname{det}^{19}$. Tekst og medie har her som udgangspunkt løsrevet sig fra hinanden. Hyperdynamiske tekstformer vil dog være meget vanskelig for den akademiske verden at operere med, eftersom det for nuværende ville være for problematisk i forhold til kildefremfinding, troværdighed og ophavsret, der kræver høj stabilitet. Derfor kan akademiske online-udgivelser synes at reintroducere printformatets fiksering af tekst for blandt andet at imødekomme copyright-lovgivning ${ }^{20}$. I forbindelse med henvisninger til digitalt materiale fastholder man derfor stabiliseringsfaktorer, der minder om trykkekulturens henvisningsform. Hvis muligt medtages bibliografisk information som forfatter, titel og udgivelsesår. Dertil kommer mere specifikke digitalt affødte referencemuligheder såsom links til digitale access-points, Digital Object Identifiers (DOI) etc., der samtidig kræver specifikke datoangivelser i forhold til fremfindingstidspunktet. Ved referencer til mere dynamiske tekstproduktioner såsom de interaktive, sociale miljøer, blogs, twitterupdates etc. kan det være nødvendigt at fastfryse referencen for at kunne dokumentere sine påstande. Her kræver det vel nærmest en fuldstændig fiksering i form af et screenshot for at kunne fastholde den tekstuelle reference, da det i de fleste tilfælde ikke er nok med specifikke datoangivelser, eftersom tekstmængden er for stor til uden for meget arbejde efterfølgende at fremfinde en specifik reference. Digitaliseringen fjerner ikke behovet for akademiske referencer og henvisninger, men fordrer måske en anden måde at dokumentere dem på. Derfor er det ikke mærkeligt, at den akademiske verden i et vist omfang stadig foretrækker at læne sig op af trykkekulturens velkendte opsætning.

\section{Tekstlegitimering}

Printtekst arbejder med en tilsyneladende stabilitet, der ikke umiddelbart er kompatibelt med dynamikken i de digitale medier (jf. O'Donnell, 1998, s.44). I forskningsøjemed udgør den fysiske bogs materialitet en klar force, fordi behovet for at kunne genfinde og tjekke kildehenvisninger er essentielt for den akademiske argumentation (Nielsen, 2012, s.72). Dette kan muligvis skabe en ambivalent holdning til digitale produktioner, for "...as readers we will want both the newest and the best... and permanence and reliability as well. We can't have both." (O'Donnell, 1998, s.49). Den tekstuelle stabilitet bliver udfordret af digitaliseringen, idet de fleste digitale tekstproduktioner har en meget kort levetid (Lyons, 2010, s.196).

Legitimering via publicering er til dels tilknyttet trykkekulturens omfattende og omkostningsrige produktionsvilkår (Tredinnick, 2009, s.38). Tekstproduktion var forbeholdt eliten og var således i sig selv indikator for værkets litterære værdi ${ }^{21}$. Daniel J. Cohen definerer forholdet mellem publicering og perception af tekst som "The Social Contract of Scholarly Publishing" (Cohen, 2012). Teksten skal som udgangspunkt gerne virke appetitvækkende på modtageren ved at fremstå sammenhængende og gennemarbejdet dvs. have en logisk fremadskridende argumentationsstruktur, en solid faglig basis og for videnskabelige artiklers vedkommende have gennemgået peer review før udgivelse. Forfatteren tager i samarbejde med udgiver og reviewere ansvaret for at producere en seriøs og bearbejdet tekst, hvis faglige indhold præsenteres på en hensigtsmæssig måde foruden at tastefejl og grammatiske fejl følgelig er 
elimineret (jf. White, 2001, s.117-119) 22. Den akademiske verden gengælder denne indsats ved at acceptere teksten som legitimt videnskabeligt værk (jf. Cohen, 2012, s.319). Forlagene tilkendegiver derfor via publiceringen, at de står inde for værkets litterære værdi. Publicering af akademiske tekster er en ressourcekrævende og omkostningsrig affære og bliver derfor ikke sat i værk, hvis ikke der er tiltro til kvaliteten af indholdet. Både forfatter, udgiver og læser opfatter den fysiske udgivelse som et kvalitetsstempel (Ibid., s.319-320).

Eftersom forfatter og udgiver står som garanter for teksten som legitimt akademisk værk, har de selvfølgelig også en interesse i, at værket indfrier modtagerens forventninger. Læserne forventer og har som minimum krav på en grammatisk korrekt, logisk sammenhængende og færdig udarbejdet tekst. I forbindelse med akademiske tekster kommer dette primært til udtryk ved en logisk sammenhængende argumentationsstruktur, hvis delelementer understøtter den overordnede problemstilling og fører hen til den endelige konklusion (jf. Dorch, 2010, s.823.

\section{Lineær tekstopbygning}

Kvalitativ tekstanalyse tilskrives hovedsageligt arbejdet med analoge værker, hvis vægtning af intensiv læsning fordrer en relativt begrænset tekstmængde (Hayles, 2012, s.12). Tekstnær analyse handler netop om at få et dybdegående kendskab til en forholdsvist lille tekstmængde. Tolkning beror på udvælgelse, analyse af og refleksion over tekstuelle nuancer og centrale tekststeder, men også på en overordnet forståelse af enkelte tekstdeles indbyrdes relationer. Langt de fleste humanistiske discipliner opererer med et sådant hermeneutisk tekstbearbejdningsideal ${ }^{24}$, hvilket kan synes truet af nye digitale læseformer (jf. Liu (Z), 2008, s.53). Den hermeneutiske tekstanalyse indeholder dog både en dybde- og en breddelæsningstilgang, hvorfor den synes kompatibel med mere digitalt understøttede læseformer.

Traditionelt set har teksten været opbygget af udsagn, der sammenkædes til kronologisk og/eller logisk at følge hinanden, hvilket forudsætter fordybelse i forbindelse med læseprocessen (Weel, 2011, $\mathrm{s} .91)^{25}$. Tekstens linearitet aktiverer langtidshukommelsen og gør det nemmere at forstå og genkalde tekstens enkelte dele, fordi de er indsat i en større meningsgivende sammenhæng (Hayles, 2012, s.64).
Narrativer og argumentationskæder fremstår ved hjælp af sprogets logik som konsistente og sammenhængende formuleringer. Den lineære fortælling som overordnet struktur har rod i en narrativ tradition, der måske er for grundlæggende og for betydningsfuld til at udgå (Landow 2006, s.265). Trykkekulturens fastfrosne tekstkonstruktion afføder en "...elaborate construction of continuity" (O'Donnell, 1998, 91), der får teksten til at fremstå sprogligt og kognitivt meningsfuld for læseren. Den strukturerede og tekstuelle rammesætning giver således mening og sammenhæng til teksten (Liu (Z), 2008, s.55).

\section{Formaliseret tekst}

Tekstens opsætning og struktur er indikatorer for tekstens værdi. Samtidig har tekstens opbygning til formål at lægge tekstens pointer frem på en hensigtsmæssig måde og derved fremme forståelsen hos læseren. Tekstens standard-udformning afspejler en gradvist opbygget og avanceret kognitiv infrastruktur, som ikke kan forventes udskiftet lige med det samme (Landow, 2006, s.265). Indholdsfortegnelse, overskrifter osv. medvirker til at give læseren overblik over indholdet. Foruden en mere eller mindre lineær rammesætning vil akademisk litteratur, hvad enten denne formidles via trykt tekst eller digitalt, indeholde intertekstuelle referencer (Landow 2006, 55). Disse kan enten komme til udtryk som eksplicitte tekstnedslag, henvisninger til værker eller traditioner eller som implicitte henvisninger, hvor narrative strukturer, temaer eller sprogbrug vækker genklang hos læseren (jf. Frow 1990, 45). Det tekstuelle fokus er vendt mod et ydre tekstapparat, men kan også bruge sin egen (kon)tekst som referenceramme. Tolkningen af tekst vil altid medtænke kontekster, der henviser til relationer i og udenfor teksten selv (Cobley \& Haeffner, 2011, s.175), idet teksten vurderes som helhed og som bestående af enkelte dele. Fodnoter, afsnit og sidetal afhjælper istedet navigationsproblemer ved at gøre det nemmere at finde rundt i, genfinde eller få uddybet specifikke tekstdele.

Printformatet tager højde for kognitive præferencer i forbindelse med afkodning af tekst, men medvirker ligeledes til at skabe og cementere disse præferencer gennem kendskab og brug (Hayles, 2012, s.65-66) ${ }^{26}$. Der er gennem trykkekulturens manifestation i printformatet skabt en kognitiv tilvænning til de læseformer og -mønstre vi benytter i dag (Burrows, 1999, s.163). Dette er ikke nogen dårlig ting. Det betyder 
tværtimod at tekstens standardudformning og den dertil knyttede læseproces er blevet modificeret og forædlet over tid. Kriterierne for teksttilegnelse er ikke på forhånd givne, men er netop menneskelige konstruktioner, historisk betingede og derfor også foranderlige (Frow, 1990, s.45). Digitaliseringen synes ikke at mindske den kritiske sans, men tværtimod snarere at udvide dens anvendelse. Medier er tilknyttet brugsformål, hvis relevans skabes, afgøres og betinges af anvendelse (jf. Säljö, 2003, 79-86). Den formaliserede, lineære fremstillingsform, der er kendetegnende for en akademisk legitim tekstproduktion, har også indflydelse for valg af de læsestrategier, der benyttes ved tilegnelse af en akademisk tekst.

\section{Læsekriterier}

Digitale medier producerer og fremstiller tekst, men i større målestoksforhold end det var tilfældet tidligere. Derfor må vi se nærmere på, hvilke implikationer en øget tekstmængde synes at have på, hvordan vi arbejder med og forstår tekst, og hvordan denne kan kombineres med dybdelæsning.

I lyset af digitaliseringen er der kommet mere fokus på tekstudvælgelse. Digitaliseringen har banet vej for en mangfoldighed af tilgængeligt materiale (O'Donnell, 1998, s.67-70). Derfor øger den behovet for forhåndsfiltrering. I trykkekulturens begrebsforståelse har kvalitativ tekstanalyse mestendels været tilskrevet efterrefleksion; diskussioner eller problematiseringer af allerede anerkendte (enkelt)værker. Den strategiske oversigtslæsnings bedømmelse af indhold er affødt af denne større tekstmængde. Det synes derfor nu nødvendigt med en forhåndsudvælgelse af tekst, fordi tekstmængden er for overvældende til at intensiv dybdelæsning i udskillelsesprocessen er mulig. Først når tekstmængden er nedkogt til en relevant og overkommelig masse, giver nærlæsning mening. Selv i forbindelse med akademiske onlineudgivelser, der underlægges kvalitetskriterier, som netop søger at sikre den videnskabelige standard, er der stadig behov for en efterfølgende aktiv udvælgelse fra modtagerens side. Udvælgelseskriterier såsom aktualitet, belysning af emne, repræsentativitet etc. afhænger alle af, hvad formålet er med læsningen af den givne tekst. Tekstudvælgelsen afhænger derfor af brugskonteksten, den påtænkes at blive indsat $\mathrm{i}^{27}$.

Digital læsning øger behovet for en mere aktiv værdisætning af tekst inden nærlæsning for alvor begynder. Forhåndsudvælgelse af tekst er grundlæggende for hele den videnskabelige vidensproduktion, eftersom forskeren altid i større eller mindre omfang vil søge inspiration til, dokumentation og empirisk belæg for sine betragtninger ved at henvise til andres vidensproduktion. Samtidig underlægges teksterne nogle af forskeren opstillede kvalitets- og relevanskriterier. Derfor bliver forskerens første møde med teksten af kvalitativt bestemmende art. Skønt den lineære tekstforståelse måske nok kan synes udfordret af digitaliseringen (Page \& Thomas, 2011, s.5), er overblik og kritisk refleksion aktuelle kriterier for læsning i digitale miljøer (Mackey, 2012, s.15-16). Disse kriterier understøttes af forskellige læsestrategier, der har forskellige funktioner i forbindelse med den akademiske tekstlæsning.

\section{Læsestrategier}

Digitaliseringen tilskrives at fremme interaktivitet, nonlineær læsning og multimodale repræsentationsformer og forbindes derfor hovedsageligt med overfladelæsning, informationssøgning og tilegnelse af kortere tekstfragmenter (Liu (Z), 2008, s.53). Computerassisteret læsning kan således finde særlig styrke i sit informationssøgningspotentiale, hvis specifikke punktnedslag tilbyder en fragmenteret læserstil, der ikke nødvendigvis tager højde for den kontekst teksten i sin helhed også præsenterer (jf. Chartier, 2005, 142). Digital tekstlæsning kan således virke fragmenteret og skabe frustration, fordi man kan frygte et tab af overblik eller mening. Digital tekstlæsning anklages for at opfatte tekster som fragmenterede informationskilder, der ikke nødvendigvis indsættes i en større meningssammenhæng. Hypertekst er i sin funktion og anvendelse møntet på ikke-sekventiel læsning. Den kan derfor synes at udfordre det klassisk-lineære narrativ, der har været associeret med printkulturen (Landow, 2006, s.265). Hypertekst kan som intertekstuel dokumentationsform givetvis anklages for at fremme afbrudt, stykvis og fragmenteret læsning, men det samme kan siges om papirformatets implicitte referencer, eksplicitte kildehenvisninger eller uddybende kommentarer ${ }^{28}$. Hvad der er fælles for både hyperlinks og referencer er dog, at disse fragmenter stadig forgrener sig fra ét fælles udgangspunkt; nemlig fra én for læseren adgangsgivende tekst.

I sin papirform fremstår trykt tekst derfor udadtil som en homogen størrelse, hvis fysiske en- og hel- 
hed tillige med det lineært opbyggede narrativ, får teksten til at ligne et sammenhængende og autonomt værk. Det lineære narrativ giver illusionen af naturlig meningsdannelse ved at fremlægge en tekstuel årsagssammenhæng, skønt tekstskabelsen sjældent selv er en stringent lineær proces (jf. Cobley \& Haeffner, 2011, s.172; Dorch, 2010, s.8). Forskningsforløbet fremkommer først lineært med den formaliserede teksts stiliserede fremstilling af forløbet. Den mere eller mindre lineære rammesætning akademisk litteratur, hvad enten denne formidles via trykt tekst eller digitalt, vil altid indeholde intertekstuelle referencer (Landow 2006, 55), og kan derfor ikke opfattes som stringent lineær. Den underliggende intertekstualitet og kritisk tekstanalytiske læsninger er dog i stedet med til at præsentere teksten som fragmentarisk og kontekstualiseret. Referencernes funktion må i særdeleshed siges at fremme fragmentarisk læsning som netop problematiseres i diskussionen af digital tekstilegnelse. Teksternes kumulative opbygning gør netop, at de altid vil henvise til relationer i og udenfor teksten selv (Cobley \& Haeffner, 2011, s. 175). Den digitale tekstbearbejdningsfunktion intensiverer digitale mediers tekstanalytiske potentiale, fordi den både muliggør præcise punktnedslag i teksten og samtidig tager højde for tekstens egen kontekst. Den fragmenterede læsning er således ikke unik for digitale læsemønstre.

Denne vekslen mellem forskellige kontekster afspejler sig i læseforløbet (Lyons, 2010, s.185; s.196) Forskere kan aldrig sige sig fri for at arbejde med fragmenter af tekst, da det netop er fragmenter af tekst, der kendetegner den akademiske vidensproduktion. Referencer, citater, henvisninger etc. har alle til formål at forankre givne udsagn i en bestemt faglig tradition, at legitimere dens akademiske værdi og at påvise et fagligt tilhørsforhold. En akademisk tekst kan således ses som et kludetæppe, hvor forfatteren kombinerer sine og andres udsagn og påstande til netop at understøtte og fremlægge en overordnet tese. Forfatteren gør således brug af tekstfragmenter, men indsætter dem også i en større meningskontekst, præcis som tilrådes ud fra et hermeneutisk tekstlæsningsideal. Indholdet består således nok af enkeltdele, tekstbidder og fragmenter, men bliver ved hjælp af forfatterens struktur og form indsat $i$ en ny og større betydningskontekst med en lineær fremlægning, der afspejles i tekstens røde tråd og argumentationsstruktur. Den dynamiske tekstforståelse beror på en anerkendelse af aktiv fortolkning og strukturering som centrale for videnstilegnelse- og produktion ${ }^{29}$.

\section{Digital lasning som kvalitativ tilgang}

Digitaliseringen kan siges at arbejde ud fra en mere ekstensiv læsestrategi (Liu (Z), 2008, s.58), hvorved den angiveligt overses som dybdeanalytisk tilgang. Katherine Hayles karakteriserer den digitale læsning som "hyperreading". En læsestrategi, der har til formål at lave en hurtig og grov filtrering af indhold (Hayles, 2012, s.62). Det kvalitative aspekt indgår således her på enkelttekstniveau med en kvalitetsbestemmelse af indholdet. Selektiv overblikslæsning er her udelukkende tilskrevet digitale læsevaners informationssøgningsbehov. Dog vil man i forbindelse med faglitteratur ligeledes benytte en selektiv læsestrategi for tilegnelse af enkeltværker; man læser gerne mere intensivt i begyndelsen og slutningen af en tekst, tillige med udvalgte steder undervejs i teksten. Denne formodning beror primært på erfaringer med faglitteraturens indledning, argumentationsstruktur og konklusion, hvis udformning har til formål at skabe klarhed over tekstens formål, og præsentere indholdet på en hensigtsmæssig måde. Læsningen af en webside kan derfor til en vis grad siges at følge disse relativt traditionelle læseforskrifter.

Katherine Hayles påpeger ved hjælp af John Guillory, hvordan "a strategic response to an informationintensive environment" tidligere har været benyttet $\mathrm{i}$ forhold til arkivistisk kildemateriale (Hayles, 2012, 61). Kvantitativ tekstanalyse benytter scanning og skimming som læsestrategier til at lave en initial værdibestemmelse af indhold. Hvor scanning har til formål hurtigt at gennemsøge teksten for nøgleord og lave relevante punktnedslag, bruges skimming som teknik til at lave en overordnet tekstgennemgang og fange essensen af teksten ${ }^{30}$. Hayles proklamerer, at disse strategiske, oversigtsgivende læseteknikker også benyttes i forbindelse med digitalt materiale. Med inddragelse af usability research påpeger hun, hvorledes læsning af websider typisk antager en F-form (Hayles, 2012, s.61-62). Websider afkodes primært ved intensiv læsning af de første par linjer, hvorefter en mere overfladisk læsning tager over. Som øjet bevæger sig længere ned på indholdet, bliver den registrerede tekst gradvist mindre, og ender med at øjet bevæger sig i en mere eller mindre vertikal linje ned over det sidste af siden. Selvom denne analyse primært tilskrives informationssøgen- 
de adfærd i forbindelse med websider, understreger den en essentiel tekstlæsningstilgang og -strategi for akademisk læsning af såvel trykte som digitalt producerede tekster. Digitale tekstlæsningsmetoder kan derfor siges at bero på kriterier fra den traditionelle tekstlæsningstraditions metoder; kritik/selektion, tekstnedslag og overblik over teksten som helhed.

Læsemetoder udvælges netop efter deres evne til at indfri formålet med at læse en given tekst (jf. Liu (Z), 2008, 55). Oversigtsgivende og dybdegående tekstlæsning er ikke uforenelige, men udfylder forskellige funktioner i forbindelse med teksttilegnelse. Den akademiske læser benytter sig i udgangspunktet af mere end blot én enkelt læsestrategi ved tilegnelse af en tekst. Intensiv dybdelæsning er koncentrationskrævende og kan derfor ikke anbefales, når man arbejder med et større tekstkorpus. Af denne grund spiller ekstensiv læsning en afgørende rolle både som initial og strategisk læsestrategi i forbindelse med kvalitativ tekstanalyse. Dels fordi den muliggør grovsortering af en større tekstmængde. Dels fordi en sådan sandblæsningsstrategi kan få tekstens samlede udtryk og opbygning til at fremstå mere klart og derved giver et større overblik. Det er derfor samspillet mellem den ekstensive og intensive læseform at en tekstanalyse kan finde sted. Tekstanalyse indeholder netop en respekt for tekstens overordnede argumentationsstruktur såvel som for dens mere specifikke indholdsdele. Specifikke tekstnedslag fremmer en forståelse for tekstens partikularitet og er med til at belyse forskellige nuancer og modsætningsforhold i teksten. Strukturen giver derimod disse delelementer mening ved at påvise indbyrdes relationer og sammenhænge i teksten. Kvalitativ tekstanalyse er et avanceret samspil mellem læsestrategier, der adresserer behov for såvel overblik som for kompleksitet.

\section{Digitale anvendelsesmuligheder}

Digitaliseringen kan sagtens understøtte det traditionelle tekstformat. Det ville dog være beklageligt, at dets tilhørsforhold til bogformatet begrænsede digital tekstforståelse til kun at indeholde dette og det informationssøgende aspekt. Derfor vil artiklen afslutningsvis komme med forslag til forskellige indsatsområder, der kunne være interessante i forhold til en udvidelse af den digitale tekstbrug.

For det første kan mere komplekse udgivelsesformer være en god inspirationskilde for digitale medier, idet disse til en vis grad begrænses af papirformatets produktionsform. Nyere publiceringer inden for det medievidenskabelige felt gør brug af antologiformen til at belyse et givent emne. Antologiformen indebærer, at hvert bidrag "may be read...in its own right, but when read in the context of the other contributions...helps generate a rich dialogue..." (Page $\&$ Thomas, 2011, s.13). Denne form understøtter således den tekstanalytiske dielektik mellem det konkrete indhold og den strukturgivende form og kan undersøge intertekstuelle sammenhænge og spændinger. Denne form for komparativ læsning af en antologi sætter således den fulde tekst også den samlede tekst indgår i en større videnskontekst, idet den forholder sig som komponent til andre teksthelheder. En sådan tekstanvendelse er ikke ikke forbeholdt digitale produktionsformer og der findes da også adskillige eksempler på trykte antologier (eks. Schreibman et al., 2004; Cope \& Phillips, 2006; Siemens \& Schreibman, 2008; Simanowski et al., 2010; Page \& Thomas, 2011; Høyrup et al., 2012; Gold, 2012) 31. $^{31}$ Denne fremstillingsform tilgodeser en fremstilling af vidensprocessen som fremkommet via et aktivt, reflekterende og pulserende vidensmiljø, der forholder sig aktivt til hinandens vidensproduktion. Den underliggende vidensopfattelse accepterer således dynamik som kendetegnende for akademisk vidensproduktion og kan derfor med fordel understøttes af en mere dynamisk præsentationsform.

Et skifte fra omfattende enkeltværker om et givent emne til kortere tekstbidrag fra forskellige forfattere er måske langt fra en realitet, men det er værd at bemærke, at artikelformen i høj grad er kompatibel med en mere dynamisk og dialektisk tekstforståelse. Robert Darnton forudser eksempelvis, at et skifte fra monografien til artiklen som foretrukken akademisk publiceringsform kan blive aktuelt inden for dele af humanvidenskaben (Darnton, 2009, s.70-72). Om Darnton med tiden vil have ret $i$ et artikelformatets volumenmæssigt mindre kompositioner vil træde $\mathrm{i}$ stedet for monografien vides endnu ikke, men kontekstualitet virker til at være højt prioriteret inden for såvel tekstanalyse som for produktionsformer.

For det andet er det værd at medtænke, hvordan digitale hyperlinks synes at være kærkomne tillæg til den akademiske dokumentationsform. Digitale udgivelser indeholder som reference- og dokumentationsfartøjer nogle helt klare fordele. Tidligere har det været en omfattende og tidskrævende proces at 
fremfinde og genfinde specifikke referencer, konsultere andre værker eller finde uddybende kommentarer til tekstuelle nøgleord. Digitale hyperlinks kan give hurtig adgang til tekstens referencer og på denne måde lette den kildekritiske læsning (jf. Chartier, 2004, s.143). Specifikke henvisninger kan fremtrylles under læsningen af en artikel med ét enkelt klik frem for at måtte opstøves manuelt gennem en lang og besværlig søgning. Hyperlinks bruges ved digitale henvisninger, men har for mig at se potentiale til at blive inkorporeret i brødteksten. På denne måde vil hyperlinks ikke længere blot spille en rolle for indeks, fod- og slutnoter, men integrere kildehenvisninger i teksten selv. Spaltningen mellem udtryk og dokumentation behøves netop ikke længere med fremkomsten af en produktionsform, der ikke kræver en sådan spaltning?

For det tredje kan digitaliseringen med fordel benyttes ved analyse af særligt komplekse tekstkonstruktioner, hvor det ville være hensigtsmæssigt at kunne inddele/opdele teksten i forskellige lag. Robert Darnton hypostaserer over udviklingen af en højavanceret digital tekstbearbejdningsform, der netop kan understøtte denne analyseform (Darnton, 2009, 76-77). Darnton foreslår en tekstuel pyramide bestående af 6 forskellige lag. Overordnet set vil teksten på første niveau præsenteres i sin helhed, hvorefter de andre niveauer kunne nuancere tekstens påstande, tilknytte undervisningsmateriale, historiske eller teoretiske kontekster og understrege tekstens dynamiske tilblivelses- og perceptionsproces ved at medtage kommentarer om og til teksten (jf. Ibid.) ${ }^{32}$.

Inddelingen af tekstuelle niveauer, hvor læseren selv kan vælge omfanget af sin læsning, er en måde, hvorpå man arbejder på og understreger tekstens strukturelle kompleksitet (Darnton, 2009, s.76) og dynamiske tilblivelsesproces. Ønskes en hurtig gennemlæsning kan man blot skimme teksten igennem på det overordnede niveau og få en fornemmelse af formålet med og indholdet af teksten. Jo flere niveauer man arbejder med, jo dybere kan man vælge at dykke ned i teksten. Hermed understreges læserens aktive møde med og fortolkning af teksten i en bearbejdningsituation. Digitaliseringen behøver således ikke at bortvende sig fra traditionel tekstanalyse og -bearbejdningsformer, men kan udvide deres anvendelse og skabe mere komplekse tekstkonstruktioner, der muliggøres med den digitalt dynamiske form.

\section{Konkluderende tanker}

Skønt mere digitalt affødte tekstbearbejdningsformer i lavere eller højere grad snart kan blive en realitet, er det vigtigt at medtænke trykkekulturens teksttradition. Digitaliseringen er ikke en radikal omvæltning, der fuldkomment formår at fjerne hidtidige konventioner, men den indsætter dem i en ny kontekst. Trykkekulturens karakteristiske lineære præsentationsform kan ikke modstilles en digitalt fragmenteret fremstillingsform, da de begge indgår som læsestrategier af analoge som digitale tekster, og ofte kombineres for at give en mere fyldestgørende læsning.

Ved en digital belysning af kvalitativ analyse åbenbares et gensidigt betingelsesforhold mellem det partikulære og det generelle ${ }^{33}$. Læsning af akademiske tekster indeholder et toleddet fokus på henholdsvis det partikulære (tekstnedslag, definitioner, referencer, nøgleord etc.) og det generelle (argumentationsstruktur og sammenhæng i teksten såvel som dens kontekst). Akademiske tekster opbygges ud fra en respekt for enhed og sammenhæng som den kommer til udtryk i den overordnede struktur, tillige med et dokumentationsbehov, der modsat indbyder til mere fragmenteret læsning. Digital tekstanalyse må forholde sig til begge disse præsentationsformer med forskellige læsestrategier, der har forskelligt formål, men som teksttilegnelsesmetoder komplimenterer hinanden. En sådan læseforståelse stemmer overens med et større fokus på tekstens dynamiske tilblivelse, hvor tekstens opbygning redegør for forskningsprocessens dynamik (via referencer etc.) og via sin lineære fremstillingsform maskerer denne dynamik.

Nærlæsning af afsluttede tekstkompositioner fremlagt $i$ en endelig, afsluttet form repræsenterer en gavnlig symbiose mellem oversigts- og dybdelæsning, der sagtens kan bringe digitale tilgange i spil. Den traditionelle tekstopbygnings strukturerende funktion behøver ikke at blive udvisket med implementeringen af digital litteratur, men kan tværtimod intensiveres af den. Tekstkonstruktionen har medvirker til at præsentere indholdet på en hensigtsmæssig og overskuelig måde grundet læserens historisk affødte evne til at følge en løbende argumentationstråd. Dette medvirker til at legitimere og give mening til teksten. Dog er der ikke nogen grund til ikke også at eksperimentere og forny sig inden for dette felt, da digitaliseringen skaber nye muligheder. Kvalitativ tekstanalyse kan sagtens understøtte en digi- 
tal tekstforståelse eller ligefrem intensivere denne analyseform. Kvalitativ tekstlæsning er et humanistisk grundvilkår, hvorfor en medtænkning af denne metode har relevans i en moderne og digitaliseret kontekst.

\section{Noter}

1. Hermed ikke sagt, at andre former for tekstproduktion ikke ligeledes kan operere med nogle af de samme faktorer, men at disse tekster hverken er fokusområde for denne artikel eller at de medtager samme problematikker i helt samme omfang, som det er tilfældet med akademisk litteratur.

2. Hvad Terje Hillesund betegner som "...a mix of technological innovation and cultural conservatism" (Hillesund, 2004, s.7).

3. "For every element of a brave new world online, there are aspects of the cowardly old world simply digitized and reissued." (Mackey, 2012, s.12).

4. "I et nyt medium gentager vi så at sige det gamle medium, indtil vi opdager det nye mediums særlige kendetegn. Herefter udnytter vi i højere grad det nye medium, og det gamle mediums træk kan efterhånden helt forsvinde" (Nielsen, 2012, s.68).

5. "...the development of digital text cycles ... will change writing, distribution and reading of texts, it will alter our understanding of texts." (Hillesund, 2004, s. 8).

6. UC Berkeley ytrer eksempelvis et ønske om at højne, udvikle og realisere e-bogens interaktive potentiale (NG, 2013).

7. Hvad hun betegner som " cognitive cues" (Drucker, 2008, s. 8).

8. "...e-books must develop into a qualitatively new medium, with new genres and new uses, before they can seriously challenge the domination of paper books" (Hillesund, 2004, s.8).
9. Denne antagelse beror på erfaringer med forskellige elektroniske artikeldatabaser, såsom Taylor and Francis online, Sage Journals Online, HeinOnline, IngentaConnect etc., hvor man kan fremfinde artikler i fuld tekst og har mulighed for at hente dem som PDF.

10. "...there is always a link between the nature of the media and the content of the message..." (Kovac \& Sebart, 2006, s.83).

11. Samme standpunkt udtrykkes af Luke Tredinnick: "the transformation of information into meaning requires the intercession of human consciousness" (Tredinnick, 2005, s. 4).

12. Skønt denne sammenlægning kan være problematisk, vil Mac og Ipad for nemheds skyld ikke udspecificeres her, men formodes at indgå i denne opremsning som henholdsvis computer og tablet.

13. Digital tekst vil i princippet omhandle alle disse medieformer, idet akademikere må formodes at bruge alle disse præsentationsformer.

14. Jf. Gadamers nytolkning af den hermeneutiske cirkel (Gadamer, 2004, s.253-254).

15. Jf. Charles Sanders Peirces forståelse af "den uendelige semiosis" (Kjørup, 2006, s.249-250).

16. Citat fra John of Salisbury, Metalogicon (1159). "We are like dwarfs sitting on the shoulders of giants. We see more, and things that are more distant, than they did, not because our sight is superior or because we are taller than they, but because they raise us up, and by their great stature add to ours." (Bleyl, 2009, s.11).

17. Kombinationen af det nye med det gamle og velkendte er således ikke kun repræsenteret ved medieformernes gensidige påvirkning, men er grundlaget for tekstproduktion.

18. En sådan tekstforståelse intensiveres i digitaliseringen med Tim O'Reillys begreb om perpetual beta (O'Reilly, 2005). 
19. For en boghistorisk udlægning af bøgernes indbyggede materialitet og det digitale tab af samme, se (Striphas, 2009, s.19-44).

20. "...electronic publishing...implies that the text is fixed, delimited, and closed so that its ownership is clearly defined and...so are the rights of the author..." (Chartier 2004,145).

21. "...printed book are highly valued artifacts, associated with some of the most fundamental values of civilized society: knowledge, education, understanding, development, democrary. Literature and culture." (Hillesund, 2004, 7).

22. Mere eksperimenterende litteratur vil dog udfordre disse regler.

23. Inden for skønlitteraturen vil der i de fleste tilfælde være et fremadskridende handlingsforløb, hvis delelementer bygger historien op og forløses i fortællingens højdepunkt.

24. Lignende antagelse synes Katherine Hayles': "... close reading...constitutes the major part of the cultural capital that literary studies relies on to prove its worth to society" (Hayles, 2012, s.58) og Michael Witmores: " ...making literary studies the gatekeeper of all disciplines..." (Witmore, 2012, s.330) at bero på.

25. Dette kan maaske forklare dybdelaesningen som gennemgaaende analyseform for humanvidenskaben.

26. "Mindsets formed by print, nurtured by print, and enabled and constrained by print" (Hayles, 2012, 1).

27. "...a strategic response to an information-intensive environment, aiming to conserve attention by quickly identifying relevant information, so that only relatively few portions of text are actually read" (Hayles, 2012, s.12).

28. "Citations are fragments that the historian alone chooses to extract, without the reader being able to know the complete context out of which they came".
29. "At fortolke og formalisere er blevet vores tidsalders to store analyseformer: sandt at sige, så kender vi ikke nogen andre" (Foucault, 2006, s.288).

30. "get the gist quickly" (Hayles, 2012, s.61).

31. Henvisninger til antologier må derfor henvise til redaktører til forskel fra monografiers gængse forfatterhenvisninger.

32. Denne form kunne ligeledes understøtte tekstanalyse af skønlitterære værker med sideløbende eller sammenflettede narrativer såsom Jonathan Safran Foers "Everything is Illuminated" (Foer, 2002).

33. Dialektikken mellem disse blev allerede teoretiseret i oplysningstiden med Immanuel Kants erkendelse af, at: "Gedanken ohne Inhalt sind leer, Anschauungen ohne Begriffe sind blind" (Kant, 1990).

\section{Referencer}

Bang, J \& Dalsgaard, C (2008). Digital Forskningsformidling - kommunikative potentialer ved at anvende web 2.0 til videnskonstruktion. I: laering \& Medier (1). Lokaliseret 12.06.2013 på WWW: http:// forskningsnettet.dk/sites/forskningsnettet.dk/files/ File/LOM/Digital_forskningsformidling.pdf.

Bang, J (2011). Hvad gør et medie til et vidensmedie? I: Nye vidensmedier. Kultur, laring og kommunikation. Frederiksberg: Samfundslitteratur.

Bleyl, MF (2009). Finding Wisdom: learning from those who are wise. Bloomington, Indiana: Xlibris Corporation.

Burrows, T (1999). The text in the machine: electronic texts in the humanities. New York : Haworth Press.

Chartier, R (2004). Languages, Books, and Reading from the Printed Word to the Digital Text. I: Critical Inquiry, årg. 31, nr. 1, 2004. Lokaliseret 10.10.2013 på WWW: http://ussc.edu.au/s/media/docs/other/ CHARTIER.pdf. 
Cobley, P \& Haeffner, N (2011). DVD and the Idea of the "Text". I: New narratives: stories and storytelling in the digital age. Lincoln: University of Nebraska Press.

Cope, B \& Phillips, A (2006). The future of the book in the digital age. Oxford: Chandos Publishing.

Darnton, R (2009). The case for books: past, present, and future. New York: PublicAffairs.

Dorch, SBF (2010). E-Science og forskningsbibliotekerne. I: Revy, årg. 33, nr. 3, 2010. Lokaliseret 29.06.2013 på WWW: http://rauli.cbs.dk/index.php/ revy/article/viewFile/2958/3037.

Drotner, K (2011). Mediehistorier. Frederiksberg: Samfundslitteratur.

Drucker, J (2008). The Virtual Codex from Page Space to E-space. I: A Companion to Digital Literary Studies, ed. Susan Schreibman and Ray Siemens. Blackwell. Lokaliseret 29.06.2013 på WWW: http:// www.digitalhumanities.org/companion/view?do cId=blackwell/9781405148641/9781405148641. $\mathrm{xml} \&$ chunk.id=ss $1-5-5 \&$ toc. depth $=1 \&$ toc. $. \mathrm{d}=\mathrm{ss} 1-5$ 5\&brand $=9781405148641$ brand.

Evans, L \& Rees, S (2012). How we think: transforming power and digital technologies. I: Understanding Digital Humanities. New York: Palgrave Macmillan.

Foer, JS (2002). Everything is Illuminated. New York: Houghton Mifflin.

Foucault, M (2006). Ordene og tingene - en arkceologi om humanvidenskaberne. Frederiksberg: Det lille Forlag.

Frow, J (1990). Intertextuality and ontology. I : Intertextuality: theories and practices. Manchester; New York : Manchester University Press.

Gadamer, HG (2004). Sandhed og Metode. Grundtrcek af en filosofisk hermeneutik. Aarhus: Systime.

Gold, MK (2012). Debates in the Digital Humanities. Minneapolis: University of Minnesota Press.
Hayles, KN (2012). How we think: digital media and contemporary technogenesis. Chicago: University of Chicago Press.

Hillesund, T (2004). Digital Text Cycles: From Medieval Manuscripts to Modern Markup. I: Journal of Digital Information, årg. 6, nr. 1, 2005. Lokaliseret 10.10.2013 på WWW: http://journals.tdl.org/jodi/index.php/jodi/article/view/62/65.

Hjørland, B (2012a). Kompetencer i forskningsbibliotekerne i historisk og aktuel belysning. Udviklingsbehov i perspektiv af digitaliseringen. I: Nordisk Tidsskrift for Informationsvidenskab og Kulturformidling, årg. 1, nr. 3, 2012. Lokaliseret 30.06.2013 på WWW: http://www.danskbiblioteksforskning. dk/2011/nr1/hjoerland.pdf.

Hjørland, B (2012b). Informations- og dokumentformidlingens teoretiske grundlag. I: Viden $i$ spil. Forskningsbibliotekers funktioner i forandring. Frederiksberg: Samfundslitteratur.

Høyrup, H et al. (2012). Viden i spil. Forskningsbibliotekers funktioner i forandring. Frederiksberg: Samfundslitteratur.

Kant, I (1990). Kritik der reinen Vernunft. Hamburg: Felix Meiner Verlag. Lokaliseret 02.06.2013 på WWW: http://gutenberg.spiegel.de/buch/3502/22.

Kjørup, S (2006). Menneskevidenskaberne. Problemer og traditioner i humanioras Videnskabsteori. Roskile: Roskilde Universitetsforlag.

Kovac, M \& Sebart, MK (2006). Towards understanding patterns of book consumption in Europe. I: The future of the book in the digital age. (ed. Cope, Bill and Phillips, Angus ) Oxford: Chandos Publishing.

Kristiansen, B (2010). Tekstproduktion og vidensproduktion. I: Dansk Universitetspcedagogisk Tidsskrift, nr. 9.

Landow, GP (2006). Hypertext 3.0: critical theory and new media in an Era of Globalization. Baltimore: Johns Hopkins University Press.

Liu, A (2008). Imagining the New Media Encounter. I: A Companion to Digital Literary Studies. Oxford: Blackwell. Lokaliseret 29.06.2013 på WWW: 
http://www.digitalhumanities.org/companion/view ?docId=blackwell/9781405148641/978140514861. xml\&chunk.id=ss 1-3-1\&toc.depth=1\&toc.id=ss 1 -31\&brand=9781405148641_brand.

Liu, Z (2008). Paper to digital: documents in the information age. Westport, Connecticut : Libraries Unlimited.

Lyons, M (2010). A history of reading and writing in the Western world. Basingstoke: Palgrave Macmillan.

Mackey, M (2012). Where in the New Literary World Are We? I: Nordisk Tidsskrift for Informationsvidenskab og Kulturformidling, årg. 1, nr. 1/2, 2012. Lokaliseret 29.06.2013 på WWW : http://ntik. dk/2012/nr1-2/Mackey.pdf.

NG, Y (2013, 20. februar). UC Berkeley researchers aim to revolutionize e-books. Lokaliseret 29.06.2013 på WWW: http://www.dailycal.org/2013/02/19/ucberkeley-researchers-aim-to-revolutionize-e-books/.

Nielsen, HJ (2012). Videnskabelig kommunikation og forskningsbiblioteker i en digital tid. I: Viden $i$ spil. Forskningsbibliotekers funktioner i forandring. Frederiksberg: Samfundslitteratur.

O'Donnell, JJ (1998). Avatars of the word: from papyrus to cyberspace. Cambridge, Massachusetts : Harvard University Press.

O'Reilly, T (30. September, 2005,). End of the Software Release Cycle I: What Is Web 2.0. Lokaliseret 28.02.2013 på WWW: http://oreilly.com/web2/archive/what-is-web-20.html?page=4\#.

Page, R \& Bronwen, T (2011). Introduction. I: New narratives: stories and storytelling in the digital age. Lincoln: University of Nebraska Press.

Page, R \& Bronwen, T (eds) (2011). New narratives: stories and storytelling in the digital age. Lincoln: University of Nebraska Press.

Säljö, R (2003). Loering i praksis - et sociokulturelt perspektiv. København: Hans Reitzel.
Schreibman, S et al. (2004). A Companion to Digital Humanities. Oxford: Blackwell Publishing.

Siemens, R \& Schreibman, S (2008). A Companion to Digital Literary Studies, ed. Ray Siemens, Susan Schreibman. Oxford: Blackwell, på WWW 14.09.2013: http://www.digitalhumanities.org/ companionDLS/.

Simanowski, R et al. (2010). Reading Moving Letters: digital literature in research and teaching. A handbook. Bielefeld: Transcript Verlag.

Sheehan, K (2013). The ebook revolution: a primer for librarians on the front lines. Santa Barbara, California: Libraries Unlimited.

Striphas, TG (2009). The late age of print: everyday book culture from consumerism to control. New York: Columbia University Press.

Tredinnick, L (2006). Digital Information Contexts: Theoretical Approaches to Understanding Digital Information. Oxford: Chandos Publishing (Oxford) Limited.

Tredinnick, L (2007). Digital Information Culture. The Individual and Society in the Digital Age. Oxford: Chandos Publishing.

Tredinnick, L (2009). The analogue library in the digital world. Professional education and the changing face of librarianship. I: Dansk Biblioteksforskning årg. 5, nr. 2/3. Lokaliseret 29.06.2013 på WWW: http://www.danskbiblioteksforskning.dk/2009/nr2-3/ Tredinnick.pdf.

Weel, A van der (2011). Changing our textual minds: towards a digital order of knowledge. Manchester, New York : Manchester University Press.

White, JB (2001). The edge of meaning. Chicago, University of Chicago Press.

Witmore, M (2012). The Ancestral Text. I: Debates in the Digital Humanities. Minneapolis: University of Minnesota Press. 